A frequent difficulty in assessing the effects of an economis instrument in environmental policy is that economic instruments are ir practice rarely used in isolation, but are combined in a package of policy measures.

Environmental policy instruments do not operate in a nationa vacuum.

\title{
THE PRINCIPLES OF ENVIRONMENTAL LAW
}

\section{Loza V.A., PGS; Melnik L.G}

In recent years, much of the EU's environmental legislation ha: been stimulated by a process of accretion. In other words, basi framework or other measures have been adopted, and subsequen legislation has been motivated by efforts to complete or supplemer those frameworks. In this sense, the EU's policy-making process ma be said partly to proceed by virtue of its own momentum. The proces by which the legislation is created is often intensely political, ar sometimes owes more to compromise and political log rolling than ts tidy applications of principle. Nonetheless, there are common polic: strands that have influenced the EU's policy making.

(a) The polluter pays. Although now well-established, the principle remains an idea of formidable obscurity. In the complicatec processes by which raw materials are first made into finishec goods and thereafter distributed to consumers, it may, after all, be difficult to identify any culpable "polluter". Real offenders sometimes exist, but the term carries a connotation of special mora opprobrium which often seems unjustifiable. The basic problem is usually not him or her, or even you, but us.

(b) Prevention. This idea essentially provides tha environmental damage should preferably be prevented rather than cured.

(c) Precaution. This latter principle essentially connotes : "moral" obligation to use good husbandry in the treatment of natura resources. It implies an approach to environmental rule making which is even more protective than that demanded by the preventive principle particularly where the consequences of inactivity are thought to bi irreversible. 
(d) Sustainable development. It should be the governing rule behind environmental legislation, and accordingly that priority should be given, for example, to re-use and recycling in waste disposal.

(e) Subsidiarity. the subsidiarity principle suggests that decision making should occur at the lowest practicable level of government.

(f) Proximity. This idea has had particular importance with respect to transfrontier shipments of waste. Its roots in that context are largely political, rather than economic or environmental, and it is likely that the provision's authors had in mind transfrontier air and water pollution rather than waste shipments.

(g) Proportionality. By this it is meant that the terms and extent of any obligations imposed must be reasonably related to the objectives which are sought.

\section{THE CONCEPTION OF MODERN INFORMATION SOCIETY}

\section{A.V. Anchurova, M-01; S.V. Glivenko}

The dramatic acceleration in the development and use of information and communication technologies during the last few years has set in motion a worldwide process of transition from the "Industrial" to the "Information Society". The depth of this process seems to have much greater social, economic and cultural implications for humanity than the industrial revolution of the past. Business, education, training, research, entertainment - indeed, all aspects of life - are increasingly affected by electronic networks and multimedia technologies, which are opening up new opportunities and challenges for all. We move towards the third millennium \& we should realize the fundamental changes brought by the "communication and information revolution". Moreover, individuals, groups and communities will need to develop not only new tools of analysis but also very different mentalities and attitudes in order to adapt to the "new" civilization based on information and knowledge.

Sure signs of Information Society are information, communications, computing \& electronic (ICCE) technologies, which are developing rapidly $\&$ played a prominent role in the global economy. 